\title{
ANALISIS DAN PENENTUAN DISTRIBUSI FLUKS NEUTRON SALURAN TEMBUS RADIAL UNTUK PENDAYAGUNAAN REAKTOR KARTINI
}

\author{
Widarto \\ Pusat Penelitian dan Pengembangan Teknologi Maju
}

\begin{abstract}
ABSTRAK
ANALISIS DAN PENENTUAN DISTRIBUSI FLUKS NEUTRON SALURAN TEMBUS RADIAL UNTUK PENDAYAGUNAAN REAKTOR KARTINI. Telah dilakukan analisis dan penentuan distribusi fluks neutron pada saluran tembus radial reaktor Kartini dengan tujuan untuk melengkapi dokumen fasilitas eksperimen dan menjadi dasar pengembangan pendayagunaan dalam pemanfaatan reaktor Kartini. Analisis dan penentuan fluks neutron dilakukan dengan menggunakan metode aktivasi neutron terhadap detektor keping.emas ( $\mathrm{Au}$ ) yang dipasang di beberapa titik jari-jari tampang lintang $(19 \mathrm{~cm})$ serta sepanjang $310 \mathrm{~cm}$ arah radial saluran tembus. Hasil perhitungan menunjukkan bahwa fluks termal berkisar antara $(8,3 \pm 0,9) \cdot 10^{5} \mathrm{n} \mathrm{cm}^{-2} \mathrm{~s}^{-1}$ sampai dengan $(6,8 \pm 0,5) \cdot 10^{7} \mathrm{n} \mathrm{cm}^{-2} \mathrm{~s}^{-1}$ sedangkan fluks neutron cepat berkisar antara $(5,0 \pm 0,2) \cdot 10^{5} \mathrm{n} \mathrm{cm}^{-2} \mathrm{~s}^{-1}$ sampai dengan $(1,43 \pm 0,6) \cdot 10^{7} \mathrm{n} \mathrm{cm}^{-2} \mathrm{~s}^{-1}$. Dengan metode analisis pencocokan kurva untuk menentukan distribusi fluks neutron dapat disimpulkan bahwa distribusi fluks neutron sepanjang saluran tembus radial berbentuk fungsi polinomial.
\end{abstract}

\begin{abstract}
DETERMINATION AND ANALYSIS OF NEUTRON FLUX DISTRIBUTION ON RADIAL PIERCING BEAM PORT FOR UTILIZATION OF KARTINI RESEACH REACTOR. Determination and analysis of neutron flux measurements on radial piercing beam port have been done as completion experimental datas document and progessing on utilization of the Kartini research reactor purposes. The analysis and determination of the neutron flux have been carried out by using Au foils detector neutron activation analysis methode which put on the radius of cross section $(19 \mathrm{~cm})$ and a long of radial piercing beam port $(310 \mathrm{~cm})$ Based on the calculation, distribution of the thermal neutron flux is around $(8,3 \pm 0,9) \cdot 10^{5}$ $n \mathrm{~cm}^{-2} \mathrm{~s}^{-1}$ to $(6,8 \pm 0,5) \cdot 10^{7} \mathrm{n} \mathrm{cm}^{-2} \mathrm{~s}^{-1}$ and fast neutron is $(5,0 \pm 0,2) \cdot 10^{5} \mathrm{ncm}^{-2} \mathrm{~s}^{-1}$ to $(1,43 \pm 0,6) \cdot 10^{7} \mathrm{n} \mathrm{cm}^{-2} \mathrm{~s}^{-1}$. Analyzing by means of curve fitting method could be concluded that the neutron flux distribution on radial piercing beam port has profiled as a polynomial curve
\end{abstract}

\section{PENDAHULUAN}

Sebagaimana reaktor riset pada umum$S_{\text {nya, reaktor Kartini memiliki berbagai }}$ macam fasilitas iradiasi/aktivasi neutron antara lain fasilitas iradiasi (FI) central timble (CT) dengan fluks neutron sebesar orde $10^{13} \mathrm{n} \mathrm{cm}^{-2} \mathrm{det}^{-1}$, FI Lazy Susan (LS) memiliki 40 lokasi sample dengan fluks neutron rerata sebesar $2,5 \times 10^{11} \mathrm{n} \mathrm{cm}^{-2} \mathrm{det}^{-1}$ dan FI Pneumatic Transfer System memiliki fluks neutron sekitar $3,5 \times 10^{11} \mathrm{n} \mathrm{cm}^{-2} \mathrm{det}^{-1}$ yang biasa dimanfaatkan untuk iradiasi cuplikan umur pendek (beberapa detik). Selain ketiga FI tersebut, reaktor Kartini juga dilengkapi dengan FI Coulomn Thermal, beamport arah tangensial, beamport tembus radial serta thermalizing coulomn, yang setiap fasilitas eksperimen tersebut mempunyai karakteristik yang berbeda-beda. Saluran tembus radial (radial piercing beamport) merupakan salah satu fasilitas eksperimen yang perlu dikaji terhadap berbagai karakteristik fenomena fisika yang terjadi, misalnya distribusi fluks neutron cepat ataupun lambat dan paparan radiasi sedemikian sehingga dapat diketahui baik secara kualitatif maupun kuantitatif 
Sebagai langkah awal, perlu dilakukan analisis dan penentuan distribusi fluks neutron baik neutron cepat maupun neutron termal pada saluran tembus radial tersebut. Salah satu metode penentuan fluks neutron adalah analisis aktivasi neutron (NAA). Beberapa foil emas diletakkan pada titik-titik lokasi yang telah ditentukan di sepanjang saluran tembus radial. Karena saluran berbentuk silinder, maka selain penempatan foil berada di titik pusat, juga diletakkan pada bagian tepi untuk mengetahui perbedaan dan karakteristik distribusi fluks neutron di berbagai titik sepanjang saluran tersebut.

Metode analisis pengaktifan neutron didasarkan atas reaksi $(n, \gamma)$ dimana inti atom setiap unsur cuplikan akan menyerap neutron dan berubah menjadi radioisotop yang dapat memancarkan radiasi sinar alfa $(\alpha)$, beta $(\beta)$ atau gamma $(\gamma)$, atau dapat juga terjadi secara serentak. Analisis spektrum energi sinar gamma bertujuan untuk menentukan jenis radioisotop dalam cuplikan. Sedang hasil pencacahan (counting) untuk perhitungan fluks neutron serta analisis pencocokan kurva (curve fitting) untuk menentukan fungsi distribusi fluks neutron pada saluran tembus radial tersebut.

\section{METODOLOGI PENELITIAN}

\section{Tempat Penelitian}

Penelitian dilakukan pada saluran tembus radial reaktor Kartini yang posisinya ditunjukkan Gambar.1, dan berbentuk silinder dengan ukuran seperti ditunjukkan pada Gambar 2. berikut (dalam bentuk dua dimensi).

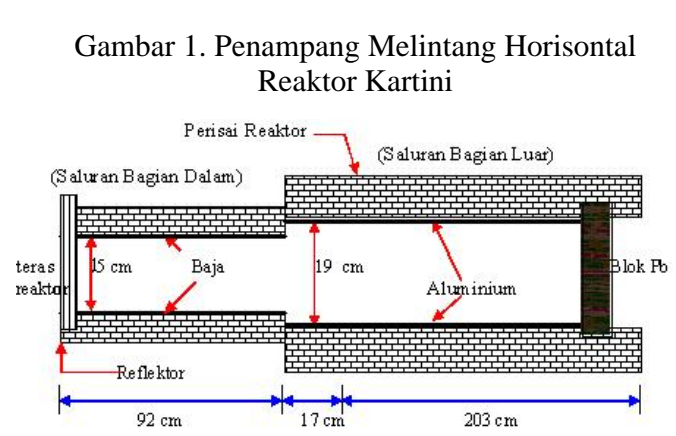

Gambar 2. Saluran Tembus Radial

\section{Tata Cara Penelitian}

\section{Tahap Persiapan}

a. Mempersiapkan dan menimbang massa foil emas (Au) sebanyak 26 keping, 13 keping diantaranya dibungkus dengan cadmium (Cd).

b. Membuat kerangka (Gambar 3) yang disesuaikan dengan bentuk saluran untuk memasang foil emas yang akan diiradiasi baik yang terbungkus cadmium maupun yang tidak terbungkus.

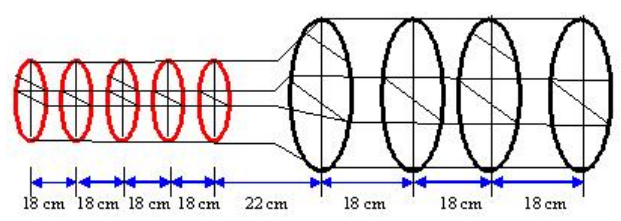

Gambar 3. Kerangka Pemegang Keping 
c. Memasang keping pada kerangka pemegang dan ditandai pada setiap posisi seperti ditunjukkan pada Gambar 2.6

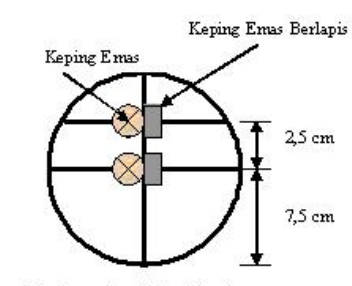

a. Lingkarankecil ( $d=14 \mathrm{~cm}$ )

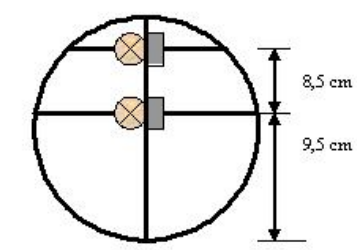

b. Lingkaran Besar ( $d=18 \mathrm{~cm})$
Gambar 4 Posisi pemasangan foil pada kerangka

d. Memberi kode pada setiap foil terpasang untuk menunjukkan posisi di dalam saluran tembus radial (Gambar 5).

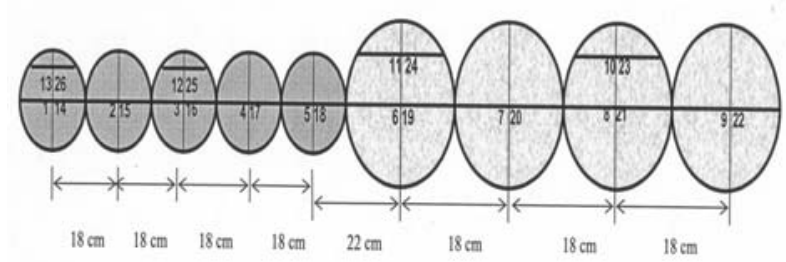

Gambar 5. Posisi Keping Setelah Diberi Kode

\section{Tahap Iradiasi}

a. Kerangka dengan foil terpasang, dimasukkan ke dalam saluran tembus radial, kemudian reaktor dioperasikan pada daya $100 \mathrm{~kW}$ selama 6 jam sebagai langkah pelaksanaan iradiasi

b. Mencatat waktu tunda sampai dengan paparan radiasi sinar gamma di sekitar saluran tembus radial kurang atau sama dengan 2,5 mrad jam ${ }^{-1}$.

c. Mengambil dan menyimpan kerangka pemegang foil ke tempat penyimpanan sementara, sampai paparan radiasi gamma dapat di lakukan pencacahan.

\section{Tahap Pencacahan}

a. Melakukan kalibrasi terhadap detektor HPGe. b. Menetapkan waktu pencacahan setiap keping (100 detik)

c. Melakukan pencacahan (counting) setiap foil emas dengan menggunakan detektor HPGe, Waktu tunda dicatat mulai saat reaktor dimatikan (shut down) sampai dengan dimulainya pencacahan.

\section{ANALISIS DATA}

\section{Penentuan Fluks Neutron}

Penentuan fluks neutron dilakukan secara tidak langsung dengan menggunakan metode analisis pengaktifan neutron. Cuplikan yang digunakan adalah foil emas terbungkus cadmium untuk menentukan fluks neutron cepat $\left(E_{n}>0,5 \mathrm{eV}\right)$ dan foil emas yang tidak terbungkus untuk menentukan fluks neutron total. Fluks neutron termal $\left(E_{n} \leq 0,5 \mathrm{eV}\right)$ ditentukan dari selisih antara fluks neutron total dan fluks neutron cepat. Untuk menentukan fluks neutron ditunjukkan oleh persamaan (1), dan persamaan (2) untuk menentukan fluks neutron termal.

$$
\begin{gathered}
\phi=\frac{\lambda \rho C}{K \sum_{a} m\left(1-e^{-\lambda t_{i}}\right) e^{-\lambda t_{d}}\left(1-e^{-\lambda t_{c}}\right)} \\
\phi_{\text {termal }}=\phi_{\text {cepat }}\left(R_{c d}-1\right) \\
R_{c d}=\frac{\phi_{\text {total }}}{\phi_{\text {cepat }}}
\end{gathered}
$$

sehingga

$$
\phi_{\text {termal }}=\phi_{\text {total }}-\phi_{\text {cepat }}
$$

keterangan :

$$
\begin{aligned}
& \sum_{a} \text { : luas penampang serapan makroskopis } \\
& \quad \text { inti }\left(\mathrm{cm}^{-1}\right)
\end{aligned}
$$

$K$ : efisiensi detektor

$\lambda$ : waktu paruh isotop radioaktif $\left(\mathrm{s}^{-1}\right)$

$t_{\mathrm{i}}$ : selang waktu iradiasi (s)

$t_{d}$ : selang waktu tunda (s)

$t_{c}$ : selang waktu pencacahan (s)

$m$ : massa isotop sebelum diiradiasi (g)

$\rho$ : massa jenis isotop sebelum diiradiasi $\left(\mathrm{g} \mathrm{cm}^{-3}\right)$. 
$R_{C d}=$ nilai banding kadmium

\section{Ketidakpastian Pengukuran Fluks Neutron}

Ketidakpastian penentuan fluks neutron dihitung dengan persamaan (5) sebagai berikut :

$$
\begin{gathered}
\Delta \phi=\frac{\lambda^{2} C \rho}{K \sum_{a} m\left(1-e^{-\lambda t_{i}}\right) \cdot e^{-\lambda t_{d}}\left(1-e^{-\lambda t_{c}}\right)} \\
\left\{\frac{|\Delta m|}{\lambda m}+\frac{e^{-\lambda t_{i}}}{1-e^{-\lambda t_{i}}}\left|\Delta t_{i}\right|+\left|\Delta t_{d}\right|+\frac{e^{-\lambda t_{c}}}{1-e^{-\lambda t_{c}}}\left|\Delta t_{c}\right|\right\} \\
\text { dan } \Delta \phi_{t}=\Delta \phi_{T}+\Delta \phi_{C} \\
\text { dengan } \Delta m=0,0005 \mathrm{~g}, \Delta t_{i}=\Delta t_{d}=\Delta t_{c}=0,5 \mathrm{~s} .
\end{gathered}
$$

\section{Faktor Koreksi}

Dalam penentuan fluks neutron dengan metode analisis pengaktifan neutron, perlu diperhatikan faktor koreksi diri yang ditunjukkan pada persamaan (7) berikut (IAEA, 1970, hal : 55-58) :

$$
F=G H
$$

dengan

$$
\begin{gathered}
G=\frac{1-P_{c}}{\left(1-P_{c}\left(1-\frac{\sum_{c}}{\sum_{t}}\right)\right)} \\
\text { dan } H=\frac{1}{\left(1+g x G\left(\frac{\sum_{c}}{\sum_{t}}\right)\right)}
\end{gathered}
$$

Keterangan :

$$
\begin{array}{lll}
G & : & \text { faktor perisai diri } \\
H & : & \text { koefisien depresi } \\
\sum_{a} & : & \text { luas penampang serapan } \\
\text { makroskopis keping } \\
\sum_{t} & : & \text { luas penampang makroskopis } \\
& \text { total keping }
\end{array}
$$

$1-P_{c}$ : kebolehjadian bahwa neutron tidak mengalami reaksi tumbukan dengan atom-atom ketika neutron menembus keping. Untuk keping berbentuk plat tipis dengan tebal $x<1 \mathrm{~cm}$,

$1-P_{c}=1-\frac{3 x}{4}-\frac{x^{2}}{6}+\frac{x^{3}}{48}+\frac{x}{2}(\ln x+\gamma)$

$\gamma$ : tetapan yang besarnya adalah 0,577216 $g$ : faktor pengali sebesar 1,0056.

Hasil perhitungan fluks neutron memberikan sekumpulan data yaitu,

$$
\left(\mathrm{x}_{0}, \phi_{0}\right),\left(\mathrm{x}_{1}, \phi_{1}\right),\left(\mathrm{x}_{2}, \phi_{2}\right), \ldots,\left(\mathrm{x}_{n}, \phi_{n}\right)
$$

\begin{tabular}{|c|c|c|c|c|}
\hline \multirow{2}{*}{\begin{tabular}{|c} 
Jarak dari \\
Teras \\
Reaktor \\
(cm)
\end{tabular}} & \multicolumn{3}{|c|}{ Fluks Neutron } & \multirow{2}{*}{$\begin{array}{c}\text { Nilai } \\
\text { Banding } \\
\text { Kadmium } \\
\left(R_{C d}\right)\end{array}$} \\
\hline & $\begin{array}{c}\text { Total } \\
\left(\mathrm{n} \mathrm{cm}^{-2} \mathrm{~s}^{-1}\right)\end{array}$ & $\begin{array}{c}\text { Termal } \\
\left.\text { (n } \mathrm{cm}^{-2} \mathrm{~s}^{-1}\right)\end{array}$ & $\begin{array}{c}\text { Cepat } \\
\left(\mathrm{n} \mathrm{cm}^{-2} \mathrm{~s}^{-1}\right)\end{array}$ & \\
\hline 0 & $\begin{array}{c}(8,2 \pm 0,4) . \\
10^{7}\end{array}$ & $\begin{array}{c}(6,8 \pm 0,5) \\
10^{7}\end{array}$ & $\begin{array}{c}(1,43 \pm 0,07) \\
10^{7} \\
\end{array}$ & 5,7 \\
\hline 18 & $\begin{array}{c}(3,4 \pm 0,2) \\
10^{7}\end{array}$ & $\begin{array}{c}(2,8 \pm 0,2) \\
10^{7}\end{array}$ & $\begin{array}{c}(5,5 \pm 0,2) \\
10^{6}\end{array}$ & 6,1 \\
\hline 36 & $\begin{array}{c}(1,65 \pm 0,08) \\
10^{7}\end{array}$ & $\begin{array}{c}(1,33 \pm 0,09) \\
10^{7}\end{array}$ & $\begin{array}{c}(3,2 \pm 0,1) \\
10^{6}\end{array}$ & 5,2 \\
\hline 54 & $\begin{array}{c}(8,6 \pm 0,4) \\
10^{6}\end{array}$ & $\begin{array}{c}(7,5 \pm 0,5) \\
10^{6}\end{array}$ & $\begin{array}{c}(1,17 \pm 0,06) \\
10^{6}\end{array}$ & 7,4 \\
\hline 72 & $\begin{array}{c}(4,3 \pm 0,3) \\
10^{6}\end{array}$ & $\begin{array}{c}(2,8 \pm 0,3) \\
10^{6}\end{array}$ & $\begin{array}{c}(1,51 \pm 0,07) \\
10^{6}\end{array}$ & 2,9 \\
\hline
\end{tabular}

Sekumpulan data ini kemudian dianalisis dengan menggunakan metode pencocokan kurva (curve fitting) untuk menentukan distribusi fluks neutron.

\begin{tabular}{|c|c|c|c|c|}
\hline \multirow{2}{*}{$\begin{array}{c}\text { Jarak dari } \\
\text { Teras } \\
\text { Reaktor } \\
\text { (cm) }\end{array}$} & \multicolumn{3}{|c|}{ Fluks Neutron } & \multirow{2}{*}{$\begin{array}{l}\text { Nilai } \\
\text { Banding } \\
\text { Kadmiu } \\
\text { m }\left(R_{c d}\right)\end{array}$} \\
\hline & $\begin{array}{c}\text { Total } \\
\left.\text { (n cm-2 } \mathrm{cm}^{-1}\right)\end{array}$ & $\begin{array}{c}\text { Termal } \\
\left(\mathrm{n} \mathrm{cm}^{-2} \mathbf{s}^{-1}\right)\end{array}$ & $\begin{array}{c}\text { Cepat } \\
\left(\mathrm{n} \mathrm{cm}^{-2} \mathrm{~s}^{-1}\right)\end{array}$ & \\
\hline 94 & $\begin{array}{c}(2,5 \pm 0,2) \\
10^{6}\end{array}$ & $\begin{array}{c}(1,8 \pm 0,2) \\
10^{6}\end{array}$ & $\begin{array}{c}(7,1 \pm 0,3) \\
10^{5}\end{array}$ & 3,5 \\
\hline 112 & $\begin{array}{c}(1,36 \pm 0,06) \\
10^{6}\end{array}$ & $\begin{array}{c}(7,8 \pm \\
0,9) \cdot 10^{5}\end{array}$ & $\begin{array}{c}(5,7 \pm 0,3) \\
10^{5}\end{array}$ & 2,4 \\
\hline 130 & $\begin{array}{c}(1,1 \pm 0,05) \\
10^{6}\end{array}$ & $\begin{array}{c}(7,1 \pm \\
0,6) \cdot 10^{5}\end{array}$ & $\begin{array}{c}(3,9 \pm 0,2) \\
10^{5}\end{array}$ & 2,9 \\
\hline 148 & $\left(\begin{array}{c}(1,34 \pm 0,07) \\
10^{6}\end{array}\right.$ & $\begin{array}{c}(8,3 \pm 0,9) \\
10^{5}\end{array}$ & $\begin{array}{c}(5,0 \pm 0,2) \\
10^{5}\end{array}$ & 2,6 \\
\hline
\end{tabular}

\section{HASIL DAN PEMBAHASAN}

\section{Hasil Perhitungan}

Hasil penentuan fluks neutron disepanjang saluran tembus radial reaktor Kartini dapat ditunjukkan pada Tabel 1. Tabel 2. dan Tabel 3. berikut ini

Tabel 1. Hasil Penentuan Fluks Neutron dan Nilai Banding Kadmium pada

Saluran Tembus Radial Bagian Dalam

Tabel 2. Hasil Penentuan Fluks Neutron dan Nilai Banding Kadmium pada Saluran Tembus Radial Bagian Luar 
Tabel 3. Hasil Penentuan Fluks Neutron dalam Arah Radial

\begin{tabular}{|c|c|c|c|c|c|}
\hline \multirow{2}{*}{$\begin{array}{l}\text { Jarak } \\
\text { dari } \\
\text { teras } \\
\text { Reaktor } \\
\text { (cm) }\end{array}$} & \multirow{2}{*}{$\begin{array}{l}\text { Letak } \\
\text { keping } \\
\text { dalam } \\
\text { arah } \\
\text { radial } \\
\text { (cm) }\end{array}$} & \multicolumn{3}{|c|}{ Fluks Neutron } & \multirow{2}{*}{$\begin{array}{c}\text { Nilai } \\
\text { Banding } \\
\text { Kadmium } \\
\left(R_{c d}\right)\end{array}$} \\
\hline & & $\begin{array}{c}\text { Total } \\
\left.\text { (n } \mathrm{cm}^{-2} \mathrm{~s}^{-1}\right)\end{array}$ & $\begin{array}{c}\text { Termal } \\
\left(\mathrm{n} \mathrm{cm}^{-2} \mathrm{~s}^{-1}\right)\end{array}$ & $\begin{array}{c}\text { Cepat } \\
\left(\mathrm{n} \mathrm{cm}^{-2} \mathrm{~s}^{-1}\right)\end{array}$ & \\
\hline 0 & $2,5 \mathrm{~cm}$ & $\left(\begin{array}{c}(7,8 \pm 0,5) \\
10^{7}\end{array}\right.$ & $\left(\begin{array}{c}(6,9 \pm 0,6) \\
10^{7}\end{array}\right.$ & $\left(\begin{array}{c}(9,8 \pm 0,6) \\
10^{6}\end{array}\right.$ & 2,5 \\
\hline 36 & $2,5 \mathrm{~cm}$ & $\begin{array}{c}(1,5 \pm 0,1) \\
10^{7}\end{array}$ & $\begin{array}{c}(1,2 \pm \\
0,1) \cdot 10^{7}\end{array}$ & $\begin{array}{c}(3,2 \pm 0,2) \\
10^{6}\end{array}$ & 2,4 \\
\hline 94 & $7,5 \mathrm{~cm}$ & $\begin{array}{c}(2,2 \pm \\
0,1) \cdot 10^{6} \\
\end{array}$ & $\begin{array}{c}(1,3 \pm \\
0,2) \cdot 10^{6}\end{array}$ & $\begin{array}{c}(8,8 \pm 0,5) \\
10^{5}\end{array}$ & 4,7 \\
\hline 130 & $7,5 \mathrm{~cm}$ & $(1,1+0,1)$ & $\left(\begin{array}{c}(7,0 \pm 0,1) \\
10^{5}\end{array}\right.$ & $\begin{array}{c}(4,5 \pm 0,2) \\
10^{5}\end{array}$ & 8,0 \\
\hline
\end{tabular}

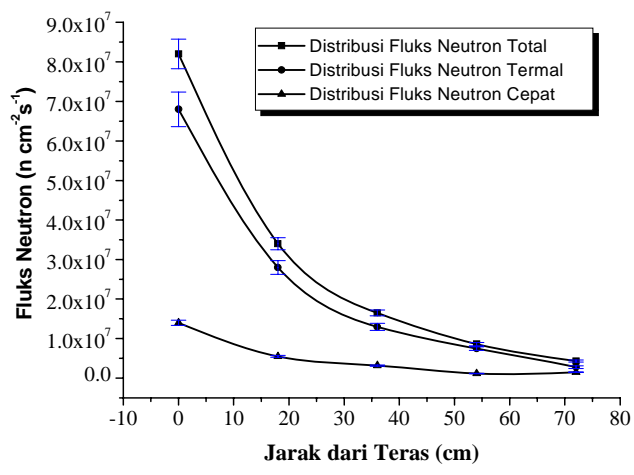

Gambar 6. Kurva Distribusi Fluks Neutron Saluran tembus Radial Bagian Dalam

\section{Pembahasan}

Distribusi fluks neutron yang meliputi fluks neutron total, fluks neutron termal dan fluks neutron cepat pada saluran tembus radial ditunjukkan oleh kurva pada Gambar 6. Gambar 7. dan gambar 8.

Dari Gambar 6. terlihat bahwa semakin jauh dari teras reactor, fluks neutron senantiasa mengalami pelemahan. Pelemahan yang paling tajam terjadi sebelum neutron mencapai jarak $80 \mathrm{~cm}$ dari teras dan setelah melewati jarak $80 \mathrm{~cm}$ pelemahan fluks neutron semakin kecil. Jika diamati lebih cermat, yaitu dengan melihat kurva pada Gambar 7, pelemahan fluks neutron total, fluks neutron termal dan fluks neutron cepat berturut-turut berakhir pada jarak $129 \mathrm{~cm}, 122 \mathrm{~cm}$ dan $136 \mathrm{~cm}$. Setelah melewati jarak tersebut, fluks neutron akan mengalami sedikit peningkatan.

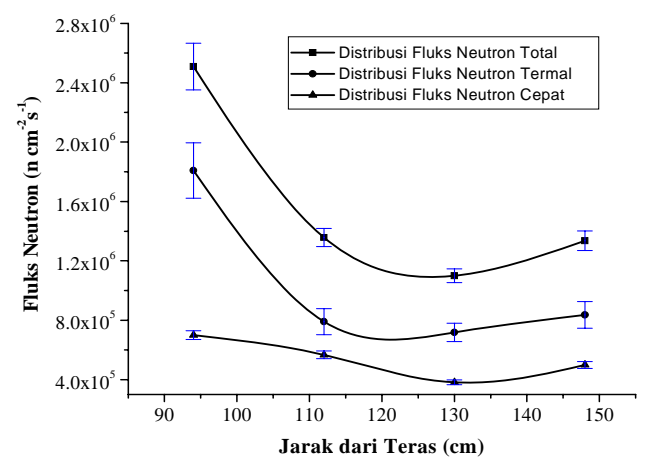

Gambar 7. Kurva Distribusi Fluks Neutron Saluran Tembus Radial Bagian Luar

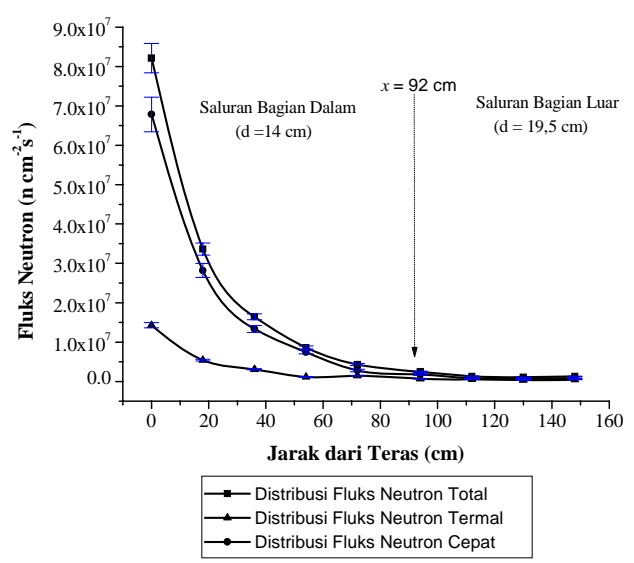

Gambar 8. Kurva Distribusi Fluks Neutron di Saluran Tembus Radial

Prosentase pelemahan fluks neutron setiap pertambahan jarak $18 \mathrm{~cm}$ dari teras reaktor ditunjukkan oleh Tabel 4 dan Tabel 5 berikut ini. 
Tabel 4. Pelemahan Fluks Neutron untuk Saluran Tembus Radial Bagian Dalam

\begin{tabular}{|c|c|}
\hline Interval jarak $(\mathbf{c m})$ & Pelemahan fluks neutron \\
\hline 0 sampai 18 & $58.5 \%$ \\
\hline 18 sampai 36 & $51.5 \%$ \\
\hline 36 sampai 54 & $47.9 \%$ \\
\hline 54 sampai 72 & $50.0 \%$ \\
\hline
\end{tabular}

Tabel 5. Pelemahan Fluks Neutron untuk Saluran Tembus Radial Bagian Luar

\begin{tabular}{|c|c|}
\hline Interval jarak $\mathbf{( c m})$ & Pelemahan fluks neutron \\
\hline 94 sampai 112 & $45.6 \%$ \\
\hline 112 sampai 130 & $19.1 \%$ \\
\hline 130 sampai 148 & $-21.8 \%$ \\
\hline
\end{tabular}

Setiap pertambahan jarak $18 \mathrm{~cm}$ dari teras reaktor, pelemahan fluks neutron total pada saluran bagian dalam berkisar antara 47,9\% sampai $58,5 \%$ dengan nilai rata-rata $52 \%$ sedangkan untuk saluran bagian luar pelemahan fluks neutron total berada di bawah $47 \%$. Hasil ini memberikan gambaran yang lebih jelas bahwa prosentase pelemahan fluks neutron pada saluran bagian dalam lebih besar daripada prosentase pelemahan fluks neutron pada saluran bagian luar.

Saluran tembus radial bagian dalam memiliki diameter $15 \mathrm{~cm}$. Lapisan yang menyelimuti dinding pada saluran tersebut adalah baja. Saluran tembus radial bagian luar memiliki diameter $19 \mathrm{~cm}$. Dinding pada saluran ini dilapisi oleh alumunium. Perbedaan ukuran diameter dan bahan pelapis berpengaruh terhadap kebolehjadian interaksi antara neutron dengan dinding saluran. Semakin kecil diameter saluran, kebolehjadian interaksi antara neutron dengan atom-atom yang melapisi dinding saluran akan semakin besar. Dalam interaksi yang terjadi, neutron mengalami perlambatan dan penyerapan oleh dinding saluran sehingga fluk neutron mengalami pelemahan. Oleh karena saluran bagian dalam memiliki diameter yang lebih kecil daripada diameter saluran bagian luar maka fluks neutron pada saluran bagian dalam fluks neutron lebih mudah mengalami pelemahan.
Tabel 5. menunjukkan bahwa fluks neutron tidak seluruhnya akan mengalami pelemahan. Pada jarak $130 \mathrm{~cm}$ sampai dengan $148 \mathrm{~cm}$ bernilai (-21,8\%) dimaksudkan fluks neutron tidak melemah tetapi justru mengalami peningkatan. Peningkatan fluks neutron ini terjadi karena saluran tembus radial diberi penyumbat dari bahan timbal $\left({ }_{82}^{207} \mathrm{~Pb}\right)$ yang berfungsi penahan radiasi gamma. Timbal (Glastone $\mathrm{S}$, et.al, 1967, hal : 58) berturut-turut memiliki luas penampang melintang mikroskopis total, serapan dan hamburan terhadap neutron sebesar 8,5 barn, 0,2 barn dan 8,3 barn. Data ini menunjukkan bahwa timbal lebih cenderung untuk menghambur-kan neutron dari pada menyerap neutron. Penempatan sumbat timbal pada saluran tembus radial menyebabkan terjadinya hamburan balik (back scattering) sehingga fluks neutron pada jarak $148 \mathrm{~cm}$ lebih tinggi daripada fluks neutron pada jarak $130 \mathrm{~cm}$.

Dari hasil perhitungan menunjukkan bahwa fluks neutron termal lebih dominan daripada fluks neutron cepat. Prosentase fluks neutron termal berkisar antara 62\% sampai dengan $86 \%$.

Pada Tabel 6. dan Tabel 7. berikut ini ditunjukkan fungsi distribusi fluks neutron dalam bentuk fungsi polinomial sebagai hasil pencocokan kurva (curve fitting) dari distribusi fluks neutron pada beamport reaktor Kartini.

Tabel 6. Fungsi Distribusi Fluks Neutron pada

Saluran Tembus Radial Bagian Dalam

\begin{tabular}{|c|c|}
\hline $\begin{array}{l}\text { a. Distribusi Fluks } \\
\text { Neutron Total }\end{array}$ & $\begin{aligned} \phi(z)= & 8,21 \cdot 10^{7}-4,20579 \cdot 10^{6} z \\
& +105952,932106791 z^{2} \\
& -1339,306127269 z^{3} \\
& +6,537208506 z^{4}\end{aligned}$ \\
\hline $\begin{array}{l}\text { b. Distribusi Fluks } \\
\text { Neutron Termal }\end{array}$ & $\begin{aligned} \phi(z)= & 6,78.10^{7}-3,28319.106 z \\
& +73200,87447785 z^{2} \\
& -778,892318106 z^{3} \\
& +3,07609933 z^{4}\end{aligned}$ \\
\hline $\begin{array}{l}\text { c. Distribusi Fluks } \\
\text { Neutron Cepat }\end{array}$ & $\begin{aligned} \phi(z) & =1,4 \cdot 10^{7}-865787,037037327 z \\
& +30078,44650208 z^{2} \\
& -513,688843165 z^{3} \\
& +3,187236448 z^{4}\end{aligned}$ \\
\hline
\end{tabular}


Tabel 7. Fungsi Distribusi Fluks Neutron pada Saluran Tembus Radial Bagian Luar

\begin{tabular}{|c|c|}
\hline $\begin{array}{l}\text { a. Distribusi Fluks } \\
\text { Neutron Total }\end{array}$ & $\begin{aligned} \phi(z)= & 3,82294.10^{7}-762633,7453577 z \\
& +5118,312761257 z^{2} \\
& -11,145404675 z^{3}\end{aligned}$ \\
\hline $\begin{array}{l}\text { b. Distribusi Fluks } \\
\text { Neutron Termal }\end{array}$ & $\begin{array}{c}\phi(z)=5,2287 \cdot 10^{7}-1,16897 \cdot 10^{6} z \\
+8763,717422794 z^{2} \\
-21,719250119 z^{3}\end{array}$ \\
\hline $\begin{array}{l}\text { c. Distribusi Fluks } \\
\text { Neutron Cepat }\end{array}$ & $\begin{aligned} \phi(z)=- & 1,2116 \cdot 10^{7} \\
& +356779,83553663 z \\
& -3230,452676 z^{2} \\
& +9,430727027 z^{3}\end{aligned}$ \\
\hline
\end{tabular}

\section{KESIMPULAN DAN SARAN}

\section{Kesimpulan}

Fluks neutron pada saluran tembus radial berkisar pada orde $10^{5}$ sampai dengan orde $10^{7} \mathrm{n} \mathrm{cm}^{-2} \mathrm{~s}^{-1}$ dan didominasi oleh fluks neutron termal. Pada saluran tersebut fungsi distribusi fluks neutron dinyatakan dalam bentuk polinomial yang dapat ditunjukkan oleh tabel 6 dan table 7. Secara keseluruhan, distribusi fluks neutron sepanjang saluran tembus radial mengalami pelemahan. Sedang pada bagian ujung mengalami sedikit peningkatan, hal ini disebabkan karena adanya hamburan neutron terhadap penyumbat timbal dalam saluran tembus radial tersebut.

\section{Saran}

Jumlah keping emas dan keping emas berlapis kadmium untuk menentukan fluks neutron agar lebih banyak lagi, sehingga diperoleh variasi jarak yang lebih banyak, agar data yang diperoleh semakin banyak sehingga distribusi fluks neutron dapat ditentukan lebih baik. Hasil penentuan distribusi fluks neutron, ini dapat digunakan sebagai dasar untuk pengembangan pemanfaatan saluran tembus radial sebagai fasilitas iradiasi neutron

Perlunya dilakukan analisis dan penentuan laju dosis radiasi gamma untuk pengkajian dan pemanfaatan eksperimen radiografi gamma

\section{DAFTAR PUSTAKA}

1. Aizawa $\mathrm{O}$, Matsumoto $\mathrm{T}$, Watanabe $\mathrm{S}$ dan Ogawa Y. 1986. Development Of A Neutron Radiography System at The Mushasi Reactor. Tokyo : Rikko University.

2. Amir Hamzah dan Ita Budi Radianti. 1993. Penentuan Faktor Perisai Diri Berbagai Keping Aktivasi Menggunakan Bentuk Spektrum Sistem Rabbit RS-1 Teras RSG-GAS. Prosiding Pertemuan dan Presentasi Ilmiah Penelitian Dasar Ilmu Pengetahuan danTeknologi Nuklir Yogyakarta, 27-29 April 1993. Buku I. Halaman : 165-168.

3. Glasstone S and Sesonske A. 1967. Nuclear Reactor Engineering. Canada : Van Nostrand Reinhold.

4. International Atomic Energy Agency (IAEA), 1970. Neutron Fluence Measurements, Viena, IAEA. 